\title{
ANALISIS PERUBAHAN INTERNAL DALAM PENGEMBANGAN KAWASAN WISATA BAHARI KEPULAUAN SAPEKEN MADURA
}

\author{
Muchammad Nurif \\ UPT PMK Sosial Humaniora, FBMT, Institut Teknologi Sepuluh Nopember \\ Email: mnurif69@gmail.com
}

\begin{abstract}
ABSTRAK
Untuk memasarkan potensi pariwisata, khususnya wisata bahari kepulauan Sapeken, perlu dibuat strategi pemasaran yang tepat untuk hasil yang optimal. Karena kepulauan Sapeken dekat dengan Bali, yang menjadi ikon pariwisata Indonesia, sehingga prospek pengembangan pariwisata, termasuk wisata bahari, sangat bagus untuk menarik wisatawan, baik wisatawan domestik maupun wisatawan asing untuk melanjutkan perjalanan mereka dari Bali ke Sapeken nusantara. Selain itu, analisis perubahan internal Bandara Trunojoyo akan segera dikembalikan di Kabupaten Sumenep, untuk digunakan secara komersial, akan memudahkan akses bagi wisatawan untuk pergi ke Kabupaten Sumenep dan pergi ke kepulauan Sapeken untuk tujuan berikutnya sejak kecamatan Sapeken di Pulau Saor, desa Sapeken, Pulau Pagerungan Besar (bekas SPBU) ada bandara dengan pendekatan tempat pemasaran. Oleh karena itu, mengetahui potensi di wilayah kecamatan Sapeken, termasuk potensi pariwisata bahari yang menyebar di sekitar kepulauan di Indonesia, dan peran sektor pariwisata pada pengaktifan ekonomi suatu daerah, perlu untuk mengetahui strategi atau model untuk pemasaran potensial di semua kegiatan pariwisata.
\end{abstract}

Key words: internal changes analysis, nautical tourism, Sapeken archipelago, marketing places.

\section{PENDAHULUAN}

Kawasan Madura yang terdiri dari empat kabupaten (Sumenep, Pamekasan, Sampang, dan Bangkalan) merupakan kawasan yang relatif tertinggal dibanding wilayah lainnya di Propinsi Jawa Timur. Hal ini tercermin dari indikator-indikator pembangunan, yang menunjukkan posisi kabupatenkabupaten di kawasan Madura tersebut berada di bawah kabupaten-kabupaten lainnya di Jawa Timur. Sudah banyak usaha untuk meningkatkan potensi kabupaten di kawasan Madura, namun upaya ini belum dapat terealisasi sampai saat ini. Terisolasinya kabupaten-kabupaten yang berada di kawasan Madura dari kabupaten/kota lain di Propinsi Jawa Timur oleh selat Madura menjadi salah satu penyebab terjadinya hal ini.

\section{ANALISIS INTERNAL DAERAH (COMPANY)}

Analisis internal Pulau Sapeken dilakukan untuk mengetahui kemampuan internal daerah yang akan digunakan untuk mendukung implementasi strategi persaingan. Yang dilakukan yaitu dengan audit sumber daya (resources):

\subsection{Sumber Daya Fisik (Physical Resources)}

Sebagai daerah kepulauan dengan gugusan pulau-pulau kecil yang indah, Pulau Sapeken memiliki kekayaan alam berupa potensi sumber daya laut perikanan, rumput laut, sumber gas alam, hutan mangrove, mutiara, konservasi rusa dan penyu, pantai pasir putih, taman laut dengan ikan hias yang indah, terumbu karang yang masih bagus (belum rusak), pantai dengan pasirnya yang putih, konservasi rusa dan penyu. 
Sumber gas alam yang terdapat di desa pagerungan telah dieksplorasi oleh perusahaan Energi Mega Persada Kangean,Ltd dan telah memberi kontribusi bagi Pendapatan Asli Daerah (PAD) Kabupaten Sumenep. Di samping itu sumber-sumber minyak baru sudah ditemukan dan belum dieksplorasi.

Meskipun kaya dengan sumber daya alam namun pembangunan di wilayah kepulauan relatif tertinggal dibandingkan wilayah daratan. Untuk mengejar ketertinggalan tersebut, pembangunan di wilayah kepulauan masuk sebagai salah satu dari lima agenda skala prioritas pembangunan di Kabupaten Sumenep. Dengan adanya ketentuan tentang prioritas tersebut, maka seluruh elemen masyarakat mulai dari tingkat desa, kecamatan maupun kabupaten memberikan perhatian terhadap hal ini.

Kekayaan alam dan kondisi alam Pulau Sapeken memiliki potensi untuk dikembangkan sebagai kawasan pariwisata. Pada hakekatnya pengembangan kawasan pariwisata merupakan respon dari perkembangan demand wisatwan pada skala dunia yang menunjukkan peningkatan minat wisatawan yang mengarah pada bahari karena memiliki prospek yang bagus ditinjau dari segi keindahan panorama alam, sumber daya alam, letak geografisnya dan infrastruktur yang ada.

Dari sisi keindahan alam, berkawasan pariwisata Di Pulau Sapeken dapat dilakukan dengan mengitari pulau-pulau yang ada dengan menggunakan perahu. Lama perjalanan dengan kapal pelayaran rakyat dalam jangkauan untuk mengitari pulau-pulau kecil dengan berpusat dari Pulau Sapeken dapat digambarkan sebagaimana terdapat pada gambar berikut.

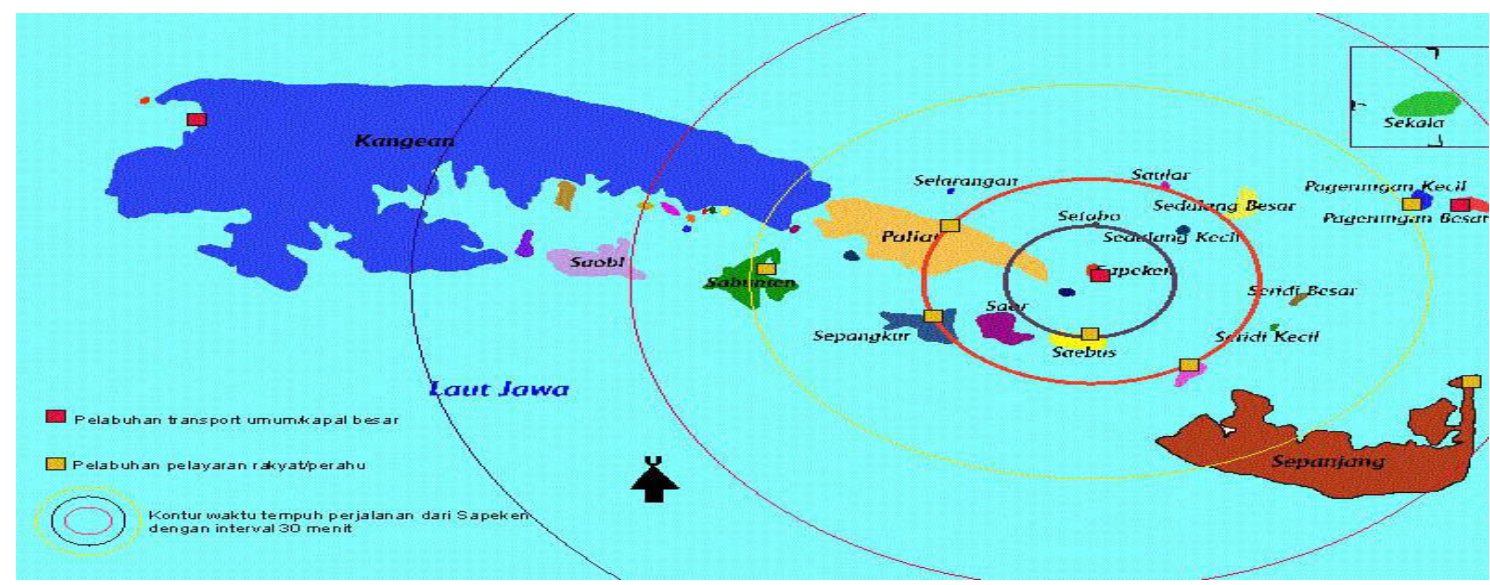

Gambar1. Lama Perjalanan Mengitari Pulau Sapeken

Keindahan alam lainnya adalah pemandangan bawah laut berupa terumbu karang yang indah dengan kondisi yang masih bagus, terdapat di Pulau Saor Desa Sapeken, Pulau Sepanjang di Desa Sepanjang, Pulau Sasiil di Desa Sasiil, Pulau Sepanjang di Desa Tanjung Kiaok, Pulau Saebus di Desa Sapeken, Pulau Sabunten di Desa Sabunten, Pulau Saebus di Desa Sapeken.(Sumenep, 2016)

Hasil penelitian kepada wisnus yang sering berkunjung ke Pulau Sapeken yaitu para divers yang sudah melakukan diving di sana, terumbu karang yang ada di Pulau Sapeken tidak kalah dengan terumbu karang yang ada di Bunaken Sulawesi Utara. Bahkan keunggulan yang ada di Sapeken adalah kondisinya yang masih bagus sedangkan yang ada di Bunaken sudah mulai rusak. Demikian juga dengan taman laut yang memiliki ikan hias yang indah dengan berbagai jenis/spesies terdapat di Pulau Sapeken dan pantai pasir putih yang indah terdapat di Pulau Saor.

Pengembangan kawasan pariwisata Pulau Sapeken tentu akan menimbulkan dampak terhadap lingkungan seperti kerusakan terumbu karang, pencemaran lingku ngan. Oleh sebab itu perlu 
dipikirkan kelestarian sumber daya yang ada dengan penataan wilayah obyek wisata da aturan yang harus dipatuhi oleh wisatawan. Di samping itu juga akan menimbulkan dampak terhadap sosial budaya masyarakat setempat. Hal ini perlu diantisipasi agar pengembangan kawasan pariwisata tidak mengorbankan budaya lokal. Dari sisi letak, P.Sapeken dan sekitarnya dapat dijangkau dari berbagai arah yaitu dari P.Bali, dari Kecamatan Kalianget di Kabupaten Sumenep, dari P.Kangean dan Banyuwangi dengan perjalanan laut. Wisatawan manca negara yang datang ke Kabupaten Pulau Sapeken merupakan wisman yang berkunjung ke Pulau Bali dengan naik Kapal PELNI atau Perahu Layar Sewa. (Sumenep, 2016)

Bali yang merupakan icon pariwisata Indonesia dan merupakan destinasi utama pariwisata dunia merupakan peluang bagi Pemkab Sumenep untuk menarik wisatawan baik wisman maupun wisnus dari Bali untuk melanjutkan perjalanan wisata ke Pulau Sapeken. Dari sisi infra struktur yang ada, adanya dua buah pelabuhan udara, di samping pelabuhan laut, lebih memungkinkan pengembangan akses menuju P.Sapeken dan sekitarnya agar lebuh cepat.

Untuk membangun dan mengembangkan kawasan pariwisata di P.Sapeken perlu perencanaan yang dilandasi oleh kerangka acuan kerja atau Term of Reference (TOR) yang jelas dengan melihat potensi yang dimiliki dan masalah yang akan timbul dari pembangunan kawasan pariwisata tersebut. Di samping itu pembangunan maupun pengembangan kawasan pariwisata harus berbasis masyarakat (community base tourism) sehingga pembangunan atau investasi yang dilakukan harus menguntungkan dan memberdayakan masyarakat setempat.

Pengembangan kawasan pariwisata yang ada di Pulau Sapeken jika dikemas secara profesional, akan memiliki daya tarik dan nilai jual bagi wisatawan baik wisatawan nusantara (wisnus) maupun wisatawan manca negara (wisman) untuk tidak hanya datang ke sana, tetapi yang lebih penting adalah menjaga pelestarian kekayaan alam yang ada sehingga dapat menjadi pengembangan pariwisata yang berkelanjutan (sustainable tourism development).

\subsection{Sumber Daya Manusia (human resources)}

Aspek yang akan dibahas dari sumber daya manusia masyarakat Sapeken meliputi : tingkat pendidikan, adaptasi dalam menghadapi perubahan lingkungan eksternal dan kondisi budaya kerja

Dilihat dari sisi tingkat pendidikan, berdasarkan data tahun 2016, sebagian besar masyarakat Sapeken tidak tamat SD sebanyak 12.611 orang $(38,74 \%)$, tamat SD sebanyak 18.456 orang $(56,70$ $\%)$, SMP sebanyak1.127 orang (3,46\%), SMA sebanyak 353 orang (1,08\%) dan S1 sebanyak 3 orang $(0,00009 \%)$. Data pendidikan penduduk Sapeken secara rinci dapat dilihat pada tabel berikut.

Tabel 1. Banyaknya penduduk menurut Jenjang Pendidikan

\begin{tabular}{|c|c|c|c|c|c|c|}
\hline \multicolumn{7}{|c|}{$\begin{array}{c}\text { Tabel. Banyaknya Penduduk Menurut Jenjang Pendidikan } \\
\text { Yang Ditamatkan }\end{array}$} \\
\hline \multirow{2}{*}{ No } & \multirow{2}{*}{ Desa } & \multicolumn{4}{|c|}{ Jenjang Pendidikan } & \multirow[b]{2}{*}{ Jumlah } \\
\hline & & SD & SMP & SMU & PT & \\
\hline ('1) & (2) & (3) & (4) & (5) & (6) & (7) \\
\hline 1 & Sabuntan & 1,885 & 44 & 7 & - & 1,936 \\
\hline 2 & Paliat & 1,426 & 25 & 9 & - & 1,460 \\
\hline 3 & Sapeken & 4,236 & 482 & 230 & 2 & 4,950 \\
\hline 4 & Sasiil & 1,825 & 15 & 18 & - & 1,858 \\
\hline 5 & Sepanjang & 2,707 & 28 & 13 & - & 2,748 \\
\hline 6 & Tanjungkiaok & 909 & 17 & 5 & - & 931 \\
\hline 7 & Pagerungan Kecil & 2,199 & 256 & 40 & 1 & 2,496 \\
\hline
\end{tabular}




\begin{tabular}{|l|l|r|r|r|r|r|}
\hline 8 & Pagerungan Besar & 2,430 & 249 & 28 & - & 2,707 \\
\hline 9 & Sakala & 839 & 11 & 3 & - & 853 \\
\hline \multicolumn{2}{|r|}{ Jumlah } & 18,456 & 1,127 & 353 & 161 & 19,939 \\
\hline \multicolumn{2}{|l|}{ Sumber : Kecamatan Sapeken Dalam Angka, 2016} \\
\hline
\end{tabular}

Jumlah TK yang ada di Kecamatan Sapeken sebanyak 19 buah dan menyebar di sembilan desa, jumlah SD/MI terdapat di sembilan desa sebanyak 62 buah. Jumlah SMP/MTs berjumlah 6 buah yang berada hanya di Desa Sapeken 4 buah, Desa Sepanjang dan Desa Pagerungan Besar masing-masing 1 buah. Untuk SMA/MA hanya ada 1 buah di Desa Sapeken.(Sumenep, 2016)

Rendahnya tingkat pendidikan penduduk untuk tingkat SMP/MTs dan SMA/MA terkait terbatasnya jumlah sekolah tersebut yang hanya di tiga desa untuk tingkat SMP/MTs dan ada di satu desa untuk tingkat SMU. Jumlah sekolah yang terbatas ini menjadi masalah karena wilayah Kecamatan terdiri dari pulau-pulau yang dapat ditempuh dengan perjalanan laut selama 0,5-2,5 jam. Hal ini perlu mendapat perhatian mengingat rendahnya sumber daya manusia biasanya berkorelasi positif dengan tingkat kesejahteraan masyarakat dan pemahaman terhadap persoalan-persoalan dan kebijakan pembangunan yang ada.

Data Badan Pusat Statistik tahun 2016 menyebutkan bahwa sektor ekonomi yang diusahakan sebagian besar rumah tangga (RT) di Sapeken adalah perikanan 4.144 RT (46,11\%), pertanian tanaman pangan 1.874 RT (20,85 \%), perkebunan 1.147 RT (12,76 \%), peternakan 207 RT (2,30\%), perdagangan 111 RT (1,23 \%) dan transportasi/ angkutan 104 RT (1,16\%) dan sisanya 1.401 RT (15,59 $\%)$ bergerak dalam sector lainnya.

Untuk meningkatkan kualitas SDM, Kabupaten Sumenep menjadi pilot project Pengembangan Ekonomi Masyarakat Pesisisr (PEMP) dari pemerintah pusat dengan mendidik putra-putri nelayan pesisir sebanyak 30 orang di Akademi Perikanan Sidoarjo agar memiliki kemampuan dan keterampilan di bidang usaha perikanan. Kegiatan PEMP didasarkan dengan pertimbangan antara lain:

1. Kondisi perairan di daerah Pulau Sapeken penuh dengan terumbu karang yang dikhawatirkan rusak akibat penagkapan ikan yang menggunakan bahan peledak dan racun potassium.

2. Menciptakan kondisi yang dapat mendukung pariwisata kelautan sehingga dapat menarik wisatawan ke Pulau Sapeken

3. Tingkat kemapuan/keterampilan SDM yang memanfaatkna potensi laut kepulauan Kecamatan Sapeken masih rendah sehingga pemanfaatan potensi kelautannya dilakukan secara sporadis.

4. Meningkatkan penghasilan masyarakat secara berkesinambungan tanpa merusak kelestarian sumber hayati yang ada.

Dalam rangka pengembangan Kawasan pariwisata Pulau Sapeken, diperlukan tenaga ahli bidang kepariwisataan. Untuk memenuhi kebutuhan SDM Pariwisata, Pemerintah Kabupaten Sumenep perlu mendidik putra-putri dari Pulau Sapeken untuk belajar ilmun kepariwisataan

Kehidupan masyarakat Sapeken yang banyak berhubungan dengan laut menyebabkan masyarakat tersebut sebagai pekerja keras dan menyukai tantangan. Meskipun tingkat pendidikan mereka rendah, tapi budaya kerja yang tinggi menyebabkan mereka dapat memenuhi kebutuhan dasar hidupnya dengan mudah. 


\subsection{Sumber Daya Keuangan (financial resources)}

Kecamatan Sapeken termasuk wilayah kepulauan yang cukup kaya. Sumber minyak dan gas alam di Pulau Pagerungan yang telah dieksplorasi memberikan pendapatan yang tidak sedikit terhadap Pemerintah Kabupaten Sumenep. Di samping itu titik-titik minyak yang baru ditemukan aka menjadikan Kecamatan Sapeken sebagai daerah kaya dan mampu membiayai pembangunan kawasan pariwisata.

Untuk mengembangkan Kawasan pariwisata Pulau Sapeken perlu juga merintis pola kerjasama antara Pemerintah Kabupaten Sumenep dengan Pemerintah Propinsi Jawa Timur dan Perguruan Tinggi antara lain dalam bentuk:

1. Kerjasama program dan pendanaan

Dalam kerjasama ini program penataan Kawasan pariwisata di Pulau Sapeken dan pendanaannya dilakukan bersama-sama anatara Pemerintah Kabupaten Sumenep dan Pemerintah Propinsi Jawa Yimur.

2. Kerjasama dalam bentuk bantuan teknis (Technical Assistance)

Dalam hal ini program dan dana dari Pemerintah Kabupaten sedangkan bantuan teknis dalam bentuk konsultasi, advis, dapat diperoleh dari perguruan tinggi yang menguasai bidang kemaritiman..

\subsection{Sumber Daya Intangibles}

Masyarakat Sapeken dapat hidup berdampingan meskipun suku, budaya mereka berbeda. Hal ini menunjukkan bahwa mereka masyarakat yang ramah dan cukup toleran dalam menerima perbedaan. Hal ini merupakan aset berharga dalam upaya pengembangan kawasan pariwisata.

\subsection{Identifikasi Berbagai Kompetensi (Pemanfaatan Sumber Daya)}

Kompetensi dan kapabilitas suatu daerah ditentukan oleh kepemimpinan pemerintah (government leadership) dalam mengarahkan pembangunan di daerahnya. Hal ini tercermin pada kemampuan daerah dalam membangun visi daerah untuk menyatukan semua komponen dalam gerak yang padu untuk mewujudkan apa yang diinginkan oleh daerah tersebut.

Di samping kepemimpinan daerah, nilai-nilai budaya yang dianut (culture \& values) suatu daerah berperan penting dalam membangun daerah. Masyarakat Sapeken yang suka bekerja keras, ulet, suka merantau dan terbiasa menghadapi tantangan merupakan modal yang bagus untuk pengembangan Pulau Sapeken.

Sebagian masyarakat Sapeken beragama Islam. Dari jumlah penduduk sebanyak 32.550 jiwa, hanya 4 orang yang beragama nasrani, sisanya beragama Islam. Hal ini menyebabkan kohesi sosial masyarakat Sapeken sangat tinggi sehingga memiliki potensi konflik yang rendah dalam mengembangkan daerah ini.

\section{ANALISIS TOWS}

Analisis TOWS sebenarnya adalah analisis SWOT. Analisis TOWS mengunakan pendekatan yang outside-in bukan inside-out, artinya dalam melihat posisi daerah terhadap pesaingnya, terlebih 
dahulu melihat berbagai perkembangan eksternalnya sebelum meninjau lingkungan internalnya. Hal ini dilakukan karena perkembangan lingkungan eksternal seperti perkembangan teknologi informasi, globalisasi pasar, perkembangan politik, berkembang dengan sangat cepat dan kian tidak menentu (turbulence). Di tengah lingkungan eksternal yang turbulence, kemampuan daerah untuk memanfaatkan peluang dan menghindari ancaman dari lingkungan eksternal bias menjadi sumber keunggulam bersaing daerah. Dengan kata lain pendekatan outside-in adalah pendekatan yang market oriented.

Setelah mengetahui keunggulan dan kelemahan lingkungan eksternal dan internal Pulau Sapeken, maka dapat diketahui factor kekuatan dan kelemahan yang dimiliki Pulau Sapeken terhadap pesaing dengan menggunakan analisis TOWS/SWOT (Threats-Oppurtunities-Weaknesses-Strenghts), meskipun penentuan factor-faktor ini ditetapkan secara relatif(Rangkuti, 2005).

Tabel 2. Analisis TOWS Kawasan pariwisata Pulau Sapeken

\begin{tabular}{|c|c|c|}
\hline Faktor Internal & $\begin{array}{l}\text { (W) Kelemahan } \\
\text { - Transportasi terbatas } \\
\text { - Jarak tempuh cukup lama } \\
\text { - SDM masih rendah } \\
\text { - Belum tersedianya akomodasi yang } \\
\text { memadai }\end{array}$ & $\begin{array}{l}\quad \text { (S) Kekuatan } \\
\text { - } \text { SDA yang melimpah } \\
\text { - } \text { Aset wisata potensial } \\
\text { - } \text { Kebijakan pemerintah yang } \\
\text { mendukung } \\
\text { - } \text { Budaya masyarakat yang terbuka } \\
\text { - } \text { Stabilitas keamanan terjamin }\end{array}$ \\
\hline $\begin{array}{l}\quad \text { (T) Ancaman } \\
\text { - } \text { Munculnya pesaing-pesaing } \\
\text { baru } \\
\text { - } \text { Rusaknya aset wisata } \\
\text { - } \text { Adanya pengaruh social budaya } \\
\text { dari luar }\end{array}$ & $\begin{array}{l}\text { Strategi WT } \\
\text { - } \quad \text { Meningkatkan pengamanan aset } \\
\text { wisata } \\
\text { - Meningkatkan pelayanan kepada TTI- } \\
\text { TDO }\end{array}$ & $\begin{array}{l}\text { Strategi ST } \\
\text { - Mengupayakan pengelolaan SDA } \\
\text { - Mengupayakan pemerintahan yang } \\
\text { market oriented } \\
\text { - Menumbuhkan jiwa enterpreneur } \\
\text { di kalangan pemerintahan }\end{array}$ \\
\hline $\begin{array}{l}\text { (O)Peluang } \\
\text { - Adanya pemberian kewena } \\
\text { ngan perencanaan pembangu } \\
\text { nan pada tingkat kecamatan } \\
\text { - Terbuka peluang investasi } \\
\text { - Potensi pengembangan SDA } \\
\text { untuk mendongkrak PAD }\end{array}$ & $\begin{array}{l}\text { Strategi wo } \\
\text { - Meningkatkan sarana pendidikan } \\
\text { tingkat menengah } \\
\text { - Mengupayakan transportasi laut yang } \\
\text { lebih cepat (speed boat) } \\
\text { - Mengupayakan sarana akomodasi } \\
\text { yang memadai }\end{array}$ & $\begin{array}{l}\text { Strategi SO } \\
\text { - Meningkatkan jumlah dan jadwal } \\
\text { Transportasi } \\
\text { - Mengupayakan alat transportasi } \\
\text { yang lebih cepat } \\
\text { - Meningkatkan kwalitas SDM } \\
\text { - Mengupayakan kenyamana } \\
\text { investasi } \\
\text { - Meningkatkan upaya menarik TTI- } \\
\text { TDO } \\
\text { - Meningkatkan upaya promosi } \\
\text { wisata }\end{array}$ \\
\hline
\end{tabular}

\section{MEMBANGUN VISI DAERAH}

Untuk memberikan fondasi bagi perumusan strategi, maka diperlukan visi sebagai basis penetapan tujuan dan target organisasi. Visi merupakan simpul atau starting point bagi seluruh upaya daerah dalam membangun strategi pemasaran.

Untuk memasarkan kawasan pariwisata Pulau Sapeken, maka perlu dibuat visi yang dirancang untuk meraih suatu tujuan di masa depan yang sangat menantang, pencapaian target yang tidak mudah, mampu merangsang antusiasme, komitmen dan kebanggaan bagi semua yang terlibat dengan arah yang jelas, realistis dan sederhana agar mudah dipahami, yaitu Pembangunan Kawasan 
pariwisata Pulau Sapeken Yang Terpadu dan Lestari Dengan Berlandaskan Nilai Agama dan Budaya Sebagai Sumber Penghidupan Bagi Kesejahteraan Masyarakat.

\section{STRATEGI (Segmentasi, Targeting dan Positioning)}

\subsection{Segmentasi}

Segmentasi merupakan strategi memetakan pasar dan berkait erat dengan pelanggan Wisata Bahari Kepulauan Sapeken yaitu pelanggan individu (tourist dan talent) dan pelanggan bisnis (investor, trader, organizer dan developer) yang akan dibidik.(Kartajaya, Hermawan, 2005)

Pada tahap ini, ditentukan cakupan (scope) pasar yaitu TTI-TDO yang akan dilayani dan dipilahpilah ke dalam segmen-segmen yang lebih kecil.

Dengan mengetahui karakteristik dari masing-masing segmen maka segmen yang akan dipilih untuk Wisata Bahari Kepulauan Sapeken adalah :

1. Pelanggan Individu

Untuk pelanggan individu segmen yang dipilih adalah multi atribut yaitu wisatawan nusantara dan wisatawan manca negara dengan tingkat ekonomi menengah ke atas.

Pelanggan bisnis

Untuk pelanggan jenis ini, segmen yang dipilih adalah psikografis dengan pertimbangan bahwa pada pelanggan bisnis dari segmen ini memiliki tujuan jelas dalam melakukan investasi di suatu daerah, yaitu investasi dilakukan karena daerah tesebut memiliki tenaga kerja murah atau karena infrastruktur tersedia, banyak tenaga terampil atau karena tenaga kerja nya murah.

Banyaknya wisman bisnis yang datang ke Indonesia merupakan peluang untuk menarik mereka berinvestasi di Kepulauan Sapeken.

\subsection{Targeting}

Terkait dengan segmentasi yang dipilih tersebut, maka target pasar yang dipilih untuk Wisata Bahari Kepulauan Sapeken adalah yang jumlahnya banyak sehingga potensial dalam memberikan pendapatan bagi daerah dan memiliki growth yang signifikan agar mampu menjamin pendapatan daerah di masa mendatang. Kelompok yang menjadi target adalah kelompok umur di bawah 55 tahun dengan pertimbangan bahwa berdasarkan data Badan Pusat Statistik, pada kurun waktu lima tahun terakhir, wisman yang datang ke Indonesia sekitar $86 \%$ adalah kelompok umur tersebut dan yang punya hobi diving, surfing dan snorkeling. Meskipun dari sisi jumlah, wisatawan yang punya hobi diving, surfing dan snorkling tidak sebesar wisatawan umum, namun sangat potensial untuk dijadikan target pasar karena terkait dengan tingkat sosial ekonominya.(Kartajaya, Hermawan, 2005)

\subsection{Positioning}

Positioning adalah strategi untuk menempatkan produk dan merek di benak pelanggan. Hal ini berkait dengan upaya membangun rasa saling percaya antara daerah dan pelanggannya. Dengan modal kepercayaan ini, suatu daerah akan selalu diingat oleh pelanggannya yaitu TTI-TDO sehingga diharapkan terjadi kunjungan ulang atau memberikan informasi secara snow ball kepada orang lain untuk berkunjung atau berinvestasi di Kepulauan Sapeken.(Kartajaya, Hermawan, 2005) 
Positioning pengembangan Wisata Bahari Kepulauan Sapeken, didasarkan pada empat kriteria pokok, yaitu : a) Customer, positioning wisata bahari Kepulauan Sapeken harus menimbulkan image positip dari TTI-TDO sehingga menimbulkan daya tarik untuk dikunjungi. b) Competitor, positioning wisata bahari Kepulauan Sapeken haruslah memiliki ciri khas sehingga mampu secara tegas membedakan diri dengan para pesaingnya. c) Change, Positioning Wisata Bahari Kepulauan Sapeken harus tahan lama dan selalu relevan walaupun terjadi berbagai perubahan di lingkungan bisnis artinya walaupun muncul pesaing-pesaing baru, wisata bahri Kepulauan Sapeken tetap menarik untuk dikunjungi.

\section{KEMAMPUAN INTERNAL DAERAH}

Artinya bahwa keunggulan wisata bahari yang dimiliki Kepulauan Sapeken sejajar atau bahkan tidak dapat ditandingi oleh wisata bahari pesaingnya.

Posisi Kepulauan Sapeken yang berdekatan dengan Pulau Bali cukup strategis untuk menarik wisatawan yang berkunjung ke Pulau Bali agar melanjutkan wisatanya ke Kepulauan Sapeken. Hal ini dengan pertimbangan bahwa wisatawan Pulau Bali mengalami kejenuhan dengan obyek wisata yang ada di sana sehingga perlu mencari obyek wisata baru yang berbeda dengan yang ada di Pulau Bali. Jumlah wisman maupun wisnus yang berkunjung ke Pulau Bali dapat dilihat pada tabel berikut.

Tabel 3. Jumlah Wisatawan Asing \& Domestik

Yang Berkunjung ke Pulau Bali, Tahun 2010-2014

\begin{tabular}{|c|c|c|c|}
\hline \multirow{2}{*}{ Tahun } & \multicolumn{3}{|c|}{ Banyak Wisatawan } \\
\cline { 2 - 4 } & Asing & Domestik & Jumlah \\
\hline$(1)$ & $(2)$ & $(3)$ & $(4)$ \\
\hline 2010 & $1,504,021$ & 537,939 & $2,041,960$ \\
\hline 2011 & $1,250,500$ & 433,800 & $1,684,300$ \\
\hline 2012 & $1,217,344$ & 353,515 & $1,570,859$ \\
\hline 2013 & $2,009,221$ & 500,661 & $2,509,882$ \\
\hline 2014 & $1,155,129$ & 253,120 & $1,408,249$ \\
\hline
\end{tabular}

Sumber : Badan Pusat Statistik Propinsi Bali,Tahun 2014

Dari tabel di atas dapat dilihat bahwa dalam kurun waktu tahun 2010-2014 jumlah wisman yang berkunjung ke Pulau Bali sekitar $37 \%$ dari total wisman yang berkunjung ke Indonesia yaitu rata-rata pertahun sebanyak 1.843 .050 orang sedangkan wisatawan domestiknya rata-rata 415.807 orang. Jika sekitar 5-10 \% wisman maupun wisnus dari Bali melanjutkan perjalanan wisata ke Kepulauan Sapeken maka efek multiplier pariwisata sangat terasa pengaruhnya bagi perekonomian daerah Kepulauan Sapeken.(Sumenep, 2016)

Selain memanfaatkan wisatawan dari Pulau Bali, dapat juga memanfaatkan wisatawan yang berkunjung ke Jawa Timur untuk berwisata ke Kepulauan Sapeken.

Tabel 4. Jumlah Wisman Yang Mengunjungi Indonesia Melalui Pintu Masuk Jawa Timur dan Rata-Rata Pengeluaran per Kunjungan, Tahun 2011-2015

\begin{tabular}{|c|c|c|c|c|c|c|c|}
\hline \multirow[t]{2}{*}{ No } & \multirow{2}{*}{ Pintu Masuk } & \multicolumn{6}{|c|}{ Jumlah Wisatawan mancanegara } \\
\hline & & 2011 & 2012 & 2013 & 2014 & 2015 & Total \\
\hline$(1)$ & $(2)$ & (3) & (4) & (5) & (6) & (7) & (8) \\
\hline 1 & Juanda & 112.513 & 112.241 & 67.627 & 75.802 & 81.409 & 554.96 \\
\hline 2 & Tanjung Perak & 26.095 & 30.947 & 18.689 & 32.131 & 33.141 & 141 \\
\hline 3 & Meneng/ Tj. Wangi & 1.749 & 1.956 & 1.732 & 1.647 & 1.86 & 8.944 \\
\hline
\end{tabular}




\begin{tabular}{|l|l|r|r|r|r|r|r|}
4 & Probolinggo & - & - & 3.465 & 3.334 & - & 6.799 \\
\hline & Total & 140.357 & 145.144 & 97.513 & 112.914 & 116.41 & 711.71 \\
\hline $\begin{array}{l}\text { Rata-rata pengeluaran (US } \\
\text { \$) (dari pintu keluar } \\
\text { Juanda) }\end{array}$ & 917.65 & 897.56 & 702.54 & 587.35 & 752.86 & - \\
\hline
\end{tabular}

Dengan melihat keempat kreiteria tersebut dan dengan pertimbangan Bali sebagai icon pariwisata Indonesia berkelas dunia, maka positioning wisata bahari Kepulauan Sapeken adalah Bali dengan tetap berpegang teguh pada nilai-nilai dan budaya Islam dan posisi Surabaya sebagai kota industri dan bisnis. Untuk mewujudkan Kepulauan Sapeken sebagai destinasi wisata dan sebagai kota bisnis dan industri perlu dibuat segitiga wisata dan bisnis unggulan di Jawa Timur yaitu Surabaya-BaliKepulauan Sapeken dengan membuat zonasi wilayah untuk wisata dan bisnis. Dengan posisi ini diharapkan wisatawan menemukan sesuatu yang lain yang tidak ditemukan di tempat wisata berkelas dunia seperti Pulau Bali, tidak hanya dari sisi objek wisatanya tetapi juga dari sisi budayanya.

Untuk menghindari dampak negatip budaya dari kunjungan wisman, perlu dibuat aturan yang tegas yaitu larangan menggunakan bikini di lokasi perkampungan penduduk.

\section{TAKTIK}

\subsection{Diferensiasi}

Diferensiasi adalah upaya membedakan diri dengan daerah pesaing dalam apa yang ditawarkan (konten), cara menawarkannya (konteks) dan infrastruktur. Ketiga basis diferensiasi tersebut harus terintegrasi, saling mendukung, saling menguatkan satu sama lain, kokoh, berkelanjutan (sustainable), dan memiliki nilai tinggi di mata TTI-TDO.(Kartajaya, Hermawan, 2005)

Dalam hal konten, ciri khas ataupun perbedaan yang dimiliki suatu obyek wisata bisa menarik wisatawan untuk berkunjung ke obyek wisata tersebut. Keunikan dan perbedaan wisata bahari Kepulauan Sapeken dengan obyek wisata lain adalah posisi Kepulauan Sapeken yang merupakan gugusan pulau dan dikelilingi oleh laut dengan kondisi alam yang masih alami. Keunikan lainnya adalah Kepulauan Sapeken meskipun berada di wilayah Kabupaten Sumenep namun suku yang dominan adalah Suku Bajo dan bahasa yang digunakan adalah Bahasa Bajo.Di samping itu ada proses pembuatan mutiara (penyuntikan warna mutiara sesuai yang diinginkan), cagar alam rusa, peternakan penyu dan ada pulau yang banyak ularnya, taman konservasi laut, pertambangan minyak yang menyebar di beberpa pulau dalam gugusan Kepulauan yang sulit ditemui di tempat lain.

Dalam hal kontek, untuk menarik wisatawan ke P.Sapeken dan sekitarnya, maka Pemerintah Kabupaten Sumenep perlu melibatkan investor yang berpengalaman dan juga didukung oleh jaringan Biro Perjalanan Wisata yang ada di Bali, Jakarta, Yogyakarta dan Surabaya. Di samping itu perlu bekerjasama dengan Pemerinta Daerah seperti Bali, Banyuwangidan Situbondo. Dinas Pariwisata Sumenep akan melakukan Survey Investigation Design (SID) dengan tujuan untuk pemetaan sarana dan prasarana dan mencari sesuatu yang perlu ditonjolkan ataupun diciptakan (create) untuk menarik wisatawan.

Dari sisi infrastruktur, pemerintah daerah perlu memikirkan kemudahan bagi wisatawan, baik dalam hal transportasi menuju Kepulauan Sapeken, kemudahan untuk mendapatkan akomodasi, komunikasi dan semua yang terkait dengan kebutuhan wisatawan. 
Hasil penelitian lapangan, saat ini transportasi menjadi kendala untuk akses ke Pulau Sapeken. Sudah saatnya Pemerintah Kabupaten Sumenep memikirkan pengadaan kapal cepat agar jarak tempuh menuju Sapeken bisa lebih singkat dan mengembangkan pemanfaatan lapangan terbang yang ada untuk transportasi udara bagi wisatawan.

\subsection{Marketing Mix}

Upaya memasarkan Wisata Bahari Kepulauan Sapeken bukanlah hal mudah. Banyak faktor yang perlu diperhatikan agar upaya pemasaran berhasil yaitu menyangkut kombinasi dari seluruh konsep pemasaran yaitu product, price, place dan promotion.

Dari sisi produk, dalam hal ini obyek wisata yang ditawarkan di Kepulauan Sapeken perlu dilakukan zonasi yang meliputi : (1) wisata taman laut, (2) olah raga Surving dan Sky Air, (3) Konservasi rusa, penyu dan peternakan mutiara, (4) wisata pantai. Zonasi ini diperlukan untuk memudahkan pengelolaan obyek wisata mengingat potensi wisata yang ada menyebar di beberapa pulau kecil.

Dari sisi harga, biaya perjalanan menuju Kepulauan Sapeken dan selama berada di Kepulauan Sapeken relatif mahal namun terjangkau untuk wisatawan. Dari sisi Place, akses menuju Kepulauan Sapeken, jika ditempuh dari Pelabuhan Meneng Banyuwangi memerlukan waktu sekitaer 8-9 jam, dari Pelabuhan Kangean dengan waktu 3-4 jam dan jika dari Pelabuhan Kalianget butuh waktu 13 jam dengan menggunakan kapal PELNI. Perjalanan menuju Pulau Sapeken dapat juga ditempuh dari Pulau Bali dengan menggunakan perahu layar sewa dengan waktu 6-8 jam. Jika menggunakan kapal cepat (speed boat), waktu perjalanan bisa ditempuh lebih cepat. Sekitar 3-4 jam. Jadwal pelayaran baik dari Banyuwangi maupun Kalianget hanya ada dua kali dalam seminggu sehingga perlu ditambah frekwensinya.

Faktor pendorong seseorang untuk mengunjungi obyek wisata adalah : (1) iklan dan promosi; (2) referensi biro perjalanan; (3) saran dan kesan dari orang lain, (4) saran dan rekomendasi dari agen.

Promosi potensi Kepulauan Sapeken telah dilakukan oleh Bupati Sumenep seperti melalui seminar baik yang diadakan di Kabupaten Sumenep maupun di luar Kabupaten Sumenep, mengikuti Majapahit Fair di Surabaya dan Gebyar Wisata Nusantara di Jakarta . Promosi yang dilakukan memang belum maksimal sehingga Pemkab Sumenep perlu memanfaatkan media promosi lain seperti media televisi, radio, iklan di koran atau mengajak biro perjalanan untuk mengunjungi obyekobyek wisata tersebut sehingga menjadikan obyek Wisata Bahari Kepulauan Sapeken dalam paket wisata yang mereka buat. Selain itu untuk lebih memperkenalkan wisata yang ada perlu dibuat event tahunan seperti mengadakan lomba selancar dan diving.

\subsection{Selling}

Selling dalam konteks pemasaran Wisata Bahari Kepulauan Sapeken adalah taktik untuk menciptakan hubungan jangka panjang dengan TTI-TDO melalui produk dan layanan yang ditawarkan. Produk dan layanan yang baik diharapkan dapat menarik pelanggan-pelanggan baru dan mempertahankan pelanggan yang sudah ada. 


\section{VALUE (Brand, Servis, Proses)}

\subsection{Brand (Merek)}

Merek merupakan value indicator yang menggambarkan seberapa kokoh dan solid nilai yang ditawarkan kepada pelanggan dan menjadi alat kunci bagi TTI-TDO dalam menetapkan pilihannya.

Brand untuk Wisata Bahari Kepulauan Sapeken adalah "Eksotisme Kepulauan Sapeken Dengan Sejuta Pesona".

\subsection{Servis}

Semua layanan yang diberikan kepada pelanggan (customer service) dimaksudkan untuk memberikan kepuasan pada pelanggan. Servis diberikan dalam upaya meningkatkan value atau nilai kepada TTI-TDO secara kontinyu.Kepuasan pelanggan dapat dicapai jika layanan yang diharapkan (expected service) pelanggan sama dengan layanan yang diterimanya.

Agar wisatawan baik domestik maupun manca negara betah tinggal di kawasan Wisata Bahari Kepulauan Sapeken, maka pelayanan yang diberikan kepada mereka harus baik. Pelayanan dapat berupa adanya informasi obyek wisata dan sarana pendukungnya, keramahan penduduk setempat, keamanan di daerah wisata, adanya jaminan kepastian hukum, tersedianya kebutuhan wisatawan seperti sarana komunikasi, transportasi, sehingga mereka bisa nyaman tinggal di daerah tersebut.

Selama ini servis yang diberikan terhadap pelanggan individu sudah cukup baik. Hal ini dapat dilihat dari adanya kunjungan ulang dari wisman maupun wisnus yang datang ke sana. Data hasil penelitian menunjukkan bahwa beberapa warga ada yang akrab dengan wisman karena wisman tersebut datang ke Kepulauan Sapeken tidak hanya sekali.

\subsection{Proses}

Proses merupakan keseluruhan aktivitas yang dijalankan oleh daerah dalam menciptakan value kepada TTI-TDO yang merefleksikan kualitas (quality), biaya (cost) dan delivery produk serta layanan yang ditawarkan oleh suatu daerah kepada TTI-TDO.(Kotler, Philip, 2003)

Agar Wisata Bahari Kepulauan Sapeken dapat menarik TTI-TDO untuk datang dan berinvestasi di sana, maka pemerintah daerah maupun masyarakat Kepulauan Sapeken harus dapat memberikan layanan yang prima yaitu cepat, mudah, biaya rendah. Untuk itu diperlukan adanya standar dan indikator kualitas pada berbagai kegiatan yang dijalankan, dengan selalu memonitor, mengevaluasi layanan yang diberikan sebagai dasar untuk mengidentifikasi bidang-bidang kegiatan yang memerlukan perbaikan, demi memuaskan pelanggan dengan cara membuat angket untuk diisi oleh wisatawan tentang persepsi mereka terhadap kualitas obyek wisata dan layanan yang mereka terima dan meminta saran tentang hal-hal yang mereka inginkan. Hal ini dilakukan secara periodik agar dari waktu ke waktu layanan yang diberikan kepada pelanggan makin baik.

Dari analisis Pengembahari Wisata Bahari Kepulauan Sapeken dengan menggunakan Strategic Place Triangle, diperoleh tiga hal inti dari konsep Marketing Places yaitu Positioning, Diferensiasi dan Brand, seperti gambar di bawah ini. 


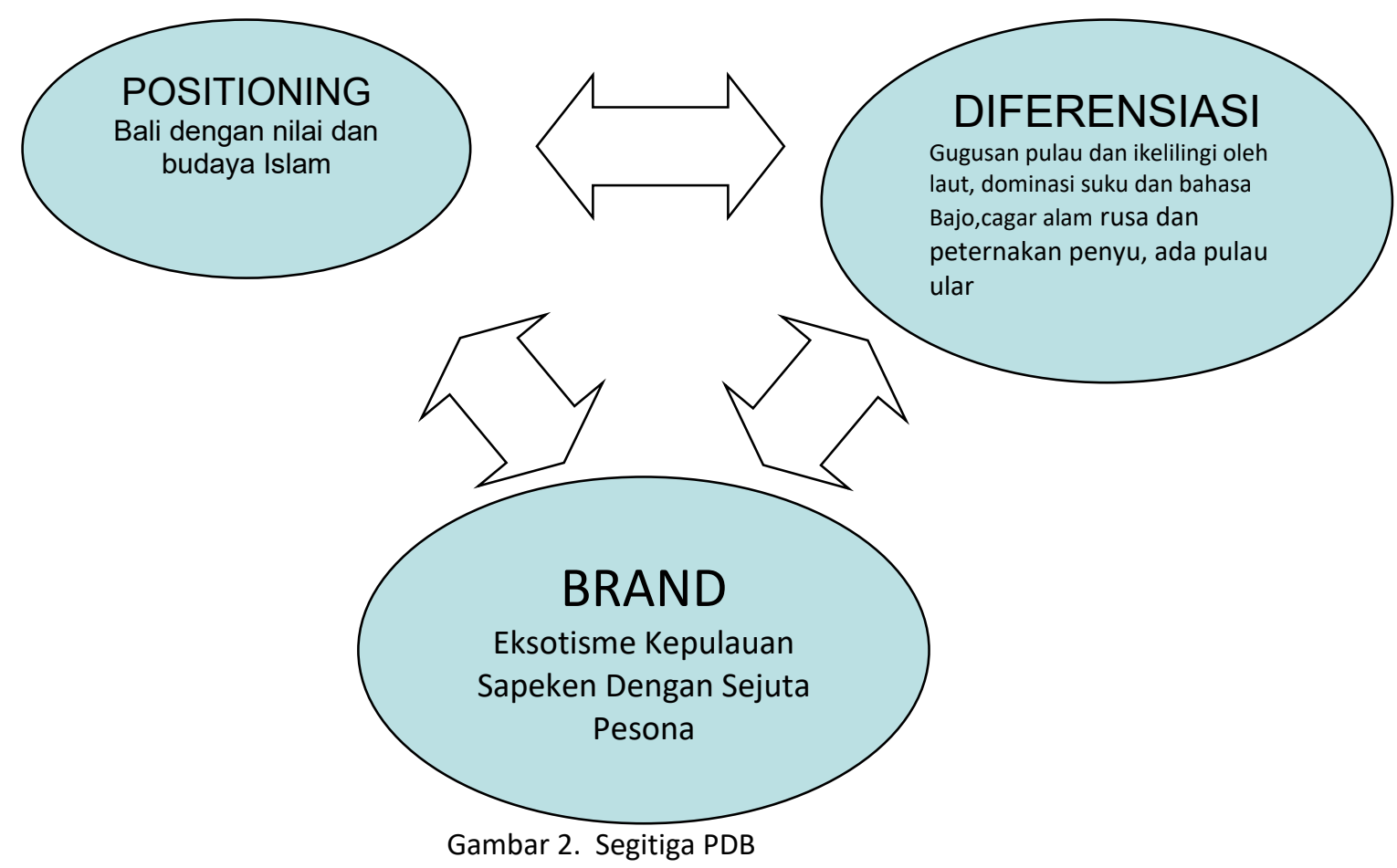

\section{KESIMPULAN}

Dari hasil analisis Pengembangan Wisata Bahari Kepulauan Sapeken dengan model Strategic Place Triangle, dapat disimpulkan :

1. Strategi Pengembangan Wisata Bahari Kepulauan Sapeken berupa segmen pasar yang dipilih adalah wisatawan nusantara dan wisatawan manca negara dengan target yang dibidik adalah kelompok masyarakat yang berumur di bawah 55 tahun dan kelompok yang punya hobi diving, surfing dan snorkeling.

2. Positioning Wisata Bahari Kepulauan Sapeken adalah Bali dengan tetap berpegang teguh pada nilai-nilai dan budaya Islam dan posisi Surabaya sebagai kota industri dan bisnis.

3. Taktik yang perlu dilakukan agar dapat menarik TTI-TDO adalah adanya deferensiasi produk dan layanan yang ditawarkan dibandingkan dengan wisata bahari di tempat.lain. Deferensiasi produk berupa posisi Kepulauan Sapeken yang merupakan gugusan pulau yang dikelilingi laut dengan kondisi alam yang masih alami. Keunikan lainnya adalah adalah dominasi Suku dan Bahasa Bajo yang digunakan masyarakat di Kepulauan Sapeken meskipun berada di wilayah Kabupaten Sumenep, adanya proses pembuatan mutiara (penyuntikan warna mutiara sesuai yang diinginkan), cagar alam rusa, peternakan penyu dan ada pulau yang banyak ularnya, taman konservasi laut, pertambangan minyak yang menyebar di beberpa pulau. Untuk memperkenalkan wisata bahari Kepulauan Sapeken perlu melibatkan investor yang berpengalaman dan juga didukung oleh jaringan Biro Perjalanan Wisata yang ada di Bali, Jakarta, Yogyakarta dan Surabaya.

4. Taktik lain yang perlu dilakukan adalah melakukan marketing mix meliputi product wisata yang bagus, price yang murah, akses menuju lokasi bisa dijangkau dengan mudah, cepat dan promotion yang gencar serta menciptakan hubungan jangka panjang dengan TTI-TDO melalui produk dan layanan yang baik kepada pelanggan. 
5. Dengan Brand "Eksotisme Kepulauan Sapeken Dengan Sejuta Pesona" diharapkan memberi image positip di benak pelanggan sehingga diharapakan memberikan nilai yang kokoh bagi Wisata Bahari Kepulauan Sapeken dalam menarik TTI-TDO

\section{SARAN}

1. Melihat potensi Wisata Bahari Kepulauan Sapeken, disarankan Pemerintah Kabupaten Sumenep segera mewujudkan pengembangan wisata tersebut dengan membenahi kekurangan yang ada baik infrastruktur, SDM maupun lokasi yang akan dijadikan pengembangan.

2. Perlu dibuat segitiga wisata Surabaya-Sumenep-Bali dengan terlebih dahulu menata lapangan terbang Trunojoyo di Sumenep dan lapangan terbang yang ada di Kepulauan Sapeken.

Disarankan pulau yang dikembangkan untuk wisata bahari adalah pulau yang penduduknya masih sedikit atau yang tidak berpenghuni untuk memperkecil masalah yang akan timbul.

\section{DAFTAR PUSTAKA}

Kartajaya, Hermawan, D. (2005). Attracting, Tourists, Traders, Investors: Strategi Memasarkan Daerah di Era Otonomi. Jakarta: MarkPlus\&Co.

Kotler, Philip, D. (2003). Rethinking Market-ing Sustainable Enterprise di Asia. Jakarta: PT Prenhallindo.

Rangkuti, F. (2005). Analisis SWOT Teknik Membedah Kasus Bisnis. Jakarta: PT SUN.

Sumenep, B. K. (2016). Kabupaten Sumenep dalam Angka 2016. sumenep: Badan Pusat Statistik. 